\title{
Formação profissional de jovens: a que se destina?
}

\author{
Manuella Castelo Branco Pessoa \\ Maria de Fátima Pereira Alberto \\ Thaís Augusta Cunha de Oliveira Máximo \\ Paulo César Zambroni de Souza \\ Universidade Federal da Paraíba
}

\begin{abstract}
Resumo
Este estudo analisa a formação profissional oferecida por uma instituição filantrópica a partir da perspectiva de jovens aprendizes. Participaram 20 jovens aprendizes, 14 do sexo feminino e seis do sexo masculino, com idades entre 15 e 22 anos, com pelo menos seis meses de experiência no Programa. Foi utilizada uma abordagem qualitativa, com realização de entrevistas semiestruturadas. As entrevistas foram analisadas por meio de análise de conteúdo temática. A partir daí identificou-se que a experiência de aprendizagem foi percebida pelos jovens como situação privilegiada para sua formação e inserção profissional. Entretanto, os autores entendem que esta formação é limitada, por se concentrar em questões comportamentais, ensinando a reproduzir e seguir as normas das empresas.
\end{abstract}

Palavras-chave: formação profissional; juventude; trabalho.

\begin{abstract}
Youth vocational training: What is for? This study examines the vocational training offered by a charity from the perspective of young apprentices. 20 young apprentices participated, 14 women and six men, aged between 15 and 22 years, with at least six months experience in the program. It was used a qualitative approach with semi-structured-interviews. The interviews were analyzed using thematic content analysis. Thereafter it was found that the learning experience was perceived by young people as a privileged position to their training and professional insertion. However, the authors believe that this training is limited because it focuses on behavioral issues, teaching to play and to follow the rules of business.
\end{abstract}

Keywords: profissional education; youth; work.

\section{Resumen}

Formación profesional de jóvenes: ¿Lo que se pretende? Este estudio examina la formación profesional ofrecida por una organización de caridad desde la perspectiva de los jóvenes aprendices. Participaron 20 jóvenes aprendices, 14 mujeres y seis hombres, de entre 15 a 22 años, con al menos seis meses de experiencia en el programa. Se utilizó un enfoque cualitativo para llevar a cabo entrevistas semi estructuradas. Entrevista analiza través análisis contenido Temática. A partir de ahí se identificó que la experiencia de aprendizaje fue percibido por los jóvenes como situación privilegiada para su formación e integración profesional. Sin embargo, los autores creen que esta formación es limitado, se centran en los problemas de comportamiento, enseñar el juego y seguir las reglas del negocio.

Palabras clave: formación; los jóvenes; trabajo.

$\mathrm{E}$ ste estudo analisa a formação profissional oferecida por uma instituição filantrópica a partir da perspectiva de jovens aprendizes. A categoria conceitual juventude tem sido alvo de inúmeros debates teóricos ao longo da história. Bastos e Carrano (2004) afirmam que jovem e juventude têm sido categorias sociais exaustivamente estudadas e constantemente redefinidas. Por muito tempo, os jovens estiveram associados à marginalidade, rebeldia

e violência, sendo considerados como fonte de problemas sociais.

Outras perspectivas trazem a juventude como uma fase da vida, sendo valorizados comportamentos de antecipação da idade adulta (Pais, 2009). Existem, no entanto, várias exigências sociais em torno dessa transição, tais como a busca da independência financeira, a escolha profissional e o casamento. 
Enquanto demarcação etária, o Instituto Brasileiro de Geografia e Estatística - IBGE, através da Pesquisa Nacional por Amostra de Domicílios - PNAD (2008), define a juventude como dividida em subgrupos: de 15 a 17 anos categoriza-se como jovem-adolescente, de 18 a 24 anos, como jovem-jovem e de 25 a 29 anos como jovem-adulto.

Contudo, a complexidade nas vivências das juventudes e nos padrões de transição para a vida adulta tem resultado em uma diminuição da probabilidade de uma sequência linear, ordenada e unidirecional de eventos da infância à velhice (Camarano, 2006). Em decorrência disso, a juventude não deve ser vista meramente como um período de transição para a vida adulta ou como o intervalo de tempo entre a adolescência e a idade adulta, ou, ainda, como o modo pelo qual os jovens deixam de ser jovens para se tornarem adultos (Constanzi, Andrade, \& Prado, 2008).

Apenas recentemente, autores (Dayrell, 2003; Guimarães, 2004; Machado, 2009) têm deixado de tratar os jovens como problemas sociais, trazendo-os ao papel de protagonistas, cidadãos e construtores da história. A partir dessa postura teórica, deixou-se de falar em juventude como uma fase de enquadramentos, e se convencionou utilizar juventudes, no plural, devido à heterogeneidade que atravessa esses sujeitos e seus meios histórico-culturais.

Para efeito deste artigo, consideramos a juventude a partir da abordagem histórico-cultural. Em sua obra, Vygotsky (1996) não delimita um conceito de juventude. Contudo, deixa clara a sua perspectiva de desenvolvimento humano. Para o autor, não existe possibilidade de universalização ou generalização do comportamento humano, tendo em vista que não se pode conceber um sujeito fora de sua história, de seu contexto e de suas relações.

Vigotski (2007) destaca que o mundo cultural no qual o jovem se constitui não é algo pronto, não é um sistema estático ao qual o sujeito fica submetido, mas um espaço de negociações, em que os membros da sociedade estão em constante movimento de recriação, de reinterpretação de informações, conceitos e significados. E a possibilidade de o jovem interagir, de se apropriar desse meio depende de suas condições concretas de existência, pode facilitar ou dificultar o acesso aos bens materiais, à educação, à cultura e à saúde, entre outras questões. Ou seja, a juventude é uma condição social, o que justifica as concepções anteriormente destacadas que postulam que não é suficiente falar em uma juventude como fase da vida e universal, mas sim em diferentes juventudes constituídas e constituintes de seus meios socioculturais.

Quando se fala em Políticas públicas para jovens, vemos que estas eram definidas a partir da filosofia de diminuição da criminalidade e da pobreza, sendo concebidas como um antídoto à marginalidade iminente. O recorte etário, econômico e social passam a reger essas políticas para jovens, porém muitas delas acabavam excluindo os que chegavam à maioridade (Sposito \& Carrano, 2003).

\section{Tecendo as relações entre juventudes, formação e trabalho}

Tomamos, com Marx, o trabalho como "um processo de que participam o homem e a natureza, processo em que o ser humano com sua própria ação impulsiona, regula e controla seu intercâmbio material com a natureza" (1999, p. 211), algo que o assinala como exclusivamente humano, pois antecipado mentalmente por quem o realiza. No entanto, quando pensamos a relação juventude/formação/trabalho no Brasil, evidenciamos que essa relação ganha formas diferentes em função do nível social, como veremos.

Diversas pesquisas empreendidas no Brasil (Frigotto, 2008; Leite, 2008; Pochmann, 2000; Wickert, 2006), identificam o trabalho como experiência obrigatória na juventude, ora representado pela busca de autonomia ou realização pessoal, ora pela necessidade financeira ou ainda sobrevivência, sendo considerado um dos marcos na transição da juventude para a idade adulta.

A pesquisa Perfil da Juventude Brasileira foi realizada em 2003 pela Fundação Perseu Abramo (2004), com jovens de 15 a 24 anos de áreas urbanas e rurais de todo o território nacional e divulgada pelo Governo Federal em 2004. Os dados demonstraram que $20 \%$ dos jovens apontaram como piores coisas da vida a falta de trabalho e de renda. Além do mais, entre os problemas que mais preocupavam os jovens, trabalho e emprego foram destacados por $52 \%$ dos participantes, sendo que $26 \%$ o apontaram como sendo o principal problema da juventude, dando destaque, inclusive, à falta de emprego.

Os dados da Pesquisa Nacional por Amostragem Domiciliar (PNAD) de 2008 confirmam a importância de se estudar a relação entre juventude e trabalho neste momento histórico específico, de novas configurações no mundo do trabalho. Andrade (2008) identifica que os índices de desempregados ou inseridos em formas precárias de trabalho (terceirizações, trabalhos temporários, sem carteira assinada, ou mesmo sem remuneração), é bem maior dentre os jovens que entre os adultos.

Acrescido a essa difícil realidade, ainda verifica-se o acesso limitado à possibilidade de qualificação profissional para os Jovens situados nas classes sócio-economicamente inferiores. A esse respeito, Pochmann (2000) constatou que o desemprego dos jovens de renda elevada é, estatisticamente, muito menor que o desemprego dos jovens de baixa renda.

Essas desigualdades em termos de qualificação e oportunidades de inserção no mercado de trabalho não são novidade. Para os jovens das classes populares, a formação para o trabalho é historicamente norteada pelo objetivo de diminuir a criminalidade e vagabundagem, como o colocam Pillotti e Rizini (1995).

Segundo Freitas e Pappa (2008), apenas a partir da segunda metade da década de 1990, os jovens começaram a conquistar relevância no espaço público brasileiro. O reconhecimento da importância da educação e qualificação para os jovens, bem como de suas dificuldades de inserção no mercado de trabalho, tem estimulado a criação de programas que aumentam a 
elevação da escolaridade, capacitação profissional e cidadania (Castro \& Aquino, 2008; Crispim \& Godoy, 2010; Pochmann, 1998).

Segundo Gonzáles (2009), as políticas para a juventude colocam-se diante de duas opções no que se refere ao trabalho: a primeira, a de preparar o jovem para fazer a transição, tentando facilitar sua contratação e oferecendo-lhes melhores oportunidades de trabalho; e a segunda, de prolongar sua escolarização, o que implica eventualmente em desincentivar a entrada do jovem no mercado de trabalho.

Prevaleceram então, as políticas com enfoque na preparação para o mercado de trabalho, com cursos de qualificação profissional que incentivam a contratação de jovens. Os empregadores veem como positivo a conclusão de um curso de formação profissional, pois estaria ligado ao "esforço", à "responsabilidade", legitimando muitas vezes o discurso da meritocracia (Gonzáles, 2009).

Para Sposati (2002), os programas sociais são caracterizados pela alta rotatividade, e este fator, por vezes, é atribuído como responsabilidade do indivíduo, que deve superar os riscos sociais. Agregado a isso, os sujeitos se sentem agradecidos por terem sido escolhidos, dentre tantos outros jovens que também necessitavam, encarando o que é um direito como uma prestação de favor.

Segundo Frezza, Maraschin e Santos (2009), a inserção em tais políticas influencia na vida do jovem, desenham, formam e instituem os modos de viver de jovens pobres na contemporaneidade. Porém, como apontam Máximo (2012), Gonzáles (2009) e Castro e Aquino (2008), essas políticas, muitas vezes, continuam a reafirmar a ideia do trabalho como "disciplinador".

Neste artigo, toma-se como referência a perspectiva de formação de Costa (2008) e Frigotto (2001, 2008), que postulam que a educação para o trabalho deve ser pensada como um instrumento de conquista da autonomia e do protagonismo juvenil, aliando a dimensão produtiva à dimensão formativa. Desse modo, formar para o trabalho não consiste em moldar o jovem de acordo com as necessidades, valores e comportamentos organizacionais, mas auxiliar na constituição do cidadão ativo e crítico.

\section{Programa jovem aprendiz}

Nos eixos de formação e qualificação se constituem as principais iniciativas públicas para os jovens, dentre elas o Programa Jovem Aprendiz (doravante será nomeado de PJA nesse artigo), objeto de estudo desta pesquisa. A contratação de aprendizes, regulamentada pela lei $\mathrm{n}^{\circ} 10.097 / 2000$ e reformulada pelo decreto $n^{\circ} 5598 / 2005$, assegura formação técnico-profissional e realização de atividades compatíveis com a vida escolar e com o desenvolvimento físico, psicológico e moral do aprendiz (Ministério do Trabalho e Emprego, 2009).

O PJA é desenvolvido por meio de atividades técnicas e práticas sob a orientação de entidades qualificadas em formação técnico-profissional. Os cursos são ministrados pelo Sistema S (Serviço Nacional de Aprendizagem Industrial - Senai,
Serviço Nacional de Aprendizagem Comercial - Senac, Serviço Nacional de Aprendizagem do Transporte - Senat, e Serviço Nacional de Aprendizagem Rural - Senar); Escolas Técnicas de Educação; Organizações não-governamentais (ONGs) ou entidades sem fins lucrativos, e têm como função fornecer ao aprendiz conhecimento teórico-prático de um determinado ofício, cujo exercício exige uma pré-qualificação.

No Brasil, em 2010, foram inseridos aproximadamente 73.000 aprendizes através das ações de fiscalização da Superintendência Nacional do Trabalho e Emprego. Na Paraíba, segundo dados coletados no Relatório da Aprendizagem de 2010 (Máximo, 2012), da Superintendência Regional do Trabalho e Emprego, 907 aprendizes foram inseridos por ação fiscal e 248 aprendizes foram contratações voluntárias das empresas. Apesar dos avanços, esses índices ainda ficam aquém do potencial do Estado que deveria ser de 11.200 jovens, em 2010.

\section{Método}

\section{Participantes}

Participaram deste estudo 20 aprendizes, tendo como critérios de inclusão na pesquisa a disponibilidade dos mesmos em participar e o tempo de inserção no programa, entre seis meses e dois anos. O fato de somente participarem da pesquisa aprendizes que estivessem no programa há pelo menos seis meses, justifica-se pela necessidade de que já tivessem um período de vivência e experiência no programa. O tempo de contrato dos aprendizes entrevistados variou de seis meses até dois anos, que é o limite máximo do programa. Porém, a maioria dos aprendizes encontrava-se inserido no programa há dois meses.

As idades variaram de 15 a 22 anos, com Moda $(\mu)$ de 16 anos de idade. Com relação ao sexo, 14 eram do sexo feminino e seis do sexo masculino. Referindo-se à escolaridade, quatro dos aprendizes tinham ensino superior incompleto, três deles com o ensino médio completo, 12 encontravam-se com ensino médio incompleto, e um declarou ter ensino Fundamental incompleto. Dos que foram entrevistados, apenas um encontrava-se com defasagem escolar, isso é, cursava uma série escolar abaixo daquela esperada para sua idade.

\section{Instrumento}

Foi utilizado um roteiro de entrevista semiestruturada, baseado em pesquisas anteriores sobre o PJA (Macedo, 2006; Santos, 2006). As perguntas se referiram a dados biopsicossociais, finalidade do programa, motivação para participar, caracterização da formação e avaliação da formação recebida.

\section{Procedimento}

Inicialmente, esta pesquisa foi submetida à Comissão de Ética do Centro de Ciências da Saúde da Universidade Federal da Paraíba, conforme determina a Resolução CNS/Ministério da Saúde do Brasil, nº 196. Uma vez aprovada pelo Comitê de Ética, foi agendada a visita à instituição formadora. 
Como forma de viabilizar o desenvolvimento da pesquisa, foi feito um primeiro contato com os responsáveis pelo desenvolvimento do PJA na Instituição Formadora em estudo. $\mathrm{Na}$ ocasião, foi realizada uma explanação a respeito dos objetivos da pesquisa e solicitada a colaboração dos aprendizes daquela instituição.

Os aprendizes, antes da realização das entrevistas, foram esclarecidos acerca da não obrigatoriedade de participação na pesquisa, do sigilo das informações obtidas e do seu anonimato. Após consentimento dos responsáveis pelos aprendizes, os termos de consentimento livre e esclarecido foram assinados. As entrevistas tiveram duração média de 20 minutos cada, e foram realizadas no espaço da própria empresa.

\section{Análise dos dados}

Os dados foram analisados através da análise de conteúdo temática, conforme apresentada por Laville e Dionne (1999), nas seguintes etapas operacionais: leitura flutuante do corpus da análise, recorte e construção das categorias analíticas, de acordo com o alicerce teórico da pesquisa, e das categorias empíricas, que se sustentam no discurso dos participantes; e, por fim, análise e interpretação das falas dos aprendizes.

\section{Resultados e discussão}

\section{Características biossociodemográficas dos partici- pantes}

No que se refere à idade, como foi destacado anteriormente, a maioria tinha 16 anos, o que está dentro da faixa etária proposta pelo Programa da Aprendizagem. Como se pode observar, a idade que prevalece entre os aprendizes é aquela em que já se permite trabalhar, conforme a Constituição Brasileira, o Estatuto da Criança e Adolescente e a Consolidação das Leis Trabalhistas - CLT; embora a idade permitida para a realização da aprendizagem profissional seja dos 14 aos 24 anos de idade.

A idade de 16 anos também foi encontrada como maioria por Macêdo (2006), em seu estudo com os jovens aprendizes no SENAC, que variavam dos 16 aos 19 anos. Esse aspecto também converge com as pesquisas de Silva (2006), que entrevistou aprendizes no SENAC, de 16 a 18 anos de idade; e em Santos (2006) que realizou a pesquisa no SENAI, com aprendizes de 14 a 23 anos.

Os participantes estavam distribuídos nos cursos de Serviços e Práticas Bancárias e Rotinas Administrativas. Quanto às atividades que os aprendizes entrevistados realizavam na empresa, foram mencionados: serviços administrativos, atendimento e retaguarda.

Em se tratando da renda familiar, desconsiderando o salário do aprendiz, encontramos quatro famílias vivendo com menos de um salário mínimo, oito famílias com mais de um até dois salários mínimos, seis com mais de dois até três salários mínimos, e um acima de sete salários mínimos. Dos vinte aprendizes, apenas um não sabia informar a renda familiar.
Temos seis famílias, com três membros, vivendo em média com $\mathrm{R} \$ 205,33$ por pessoa, oito famílias, com quatro membros, vivendo em média com $\mathrm{R} \$ 189,68$ por pessoa e cinco famílias, com cinco pessoas, vivendo com $\mathrm{R} \$ 209,20$ em média por membro familiar.

Quanto à ocupação dos pais, 13 deles relataram que os pais trabalham, enquanto seis disseram que os pais encontram-se desempregados e um que o pai encontra-se aposentado por invalidez. Os 13 pais empregados trabalham com prestação de serviços, guarda e vigilância. Vale destacar o grande número de desempregados, o que pode ser um dos fatores pelo qual o programa da aprendizagem é procurado por esses jovens. Tratando-se das mães dos aprendizes, 13 delas trabalham com atividades no comércio e prestando serviços, e as demais se encontram desempregadas.

\section{Finalidade do programa jovem aprendiz}

Os aspectos que emergiram a partir das falas, no que se refere à categoria finalidade do PJA foram: capacitação do jovem para o mercado de trabalho; oportunidade ao jovem; inclusão no mercado de trabalho; auxílio à família com baixa renda; e adequação do caráter do jovem.

A capacitação profissional, possibilitando uma primeira experiência, comprovada em carteira de trabalho, remete à aprendizagem de elementos que possam inseri-los no mercado de trabalho, como é expresso por uma das jovens quando afirma que "é importante, pois nos capacita para o mercado de trabalho" (Sexo feminino, 16 anos).

Relacionado a isso, os jovens apontam a experiência que o PJA poderá oportunizar um emprego, já que a mesma se mostra como um dos aspectos destacado pelos próprios aprendizes como cobrado e valorizado no momento da contratação. Como ressalta uma das falas: "Experiência é tudo hoje em dia" (Sexo Feminino, 22 anos).

Conforme alguns afirmaram, a formação oferece a oportunidade de ter um primeiro emprego, tendo em vista que a experiência como aprendiz possibilitaria outras oportunidades futuramente. Nesse sentido, a experiência e o primeiro emprego são destacados por uma aprendiz, quando afirma: "Eu acho muito bom, porque é uma experiência a mais que eu não tinha, porque é meu primeiro emprego" (Sexo feminino, 16 anos).

Castro e Aquino (2008) destacam que a juventude foi tradicionalmente tematizada e permanece assim até os dias de hoje, como fase transitória para a vida adulta, e por isso exige o esforço coletivo - principalmente da família e da escola - no sentido de preparar o jovem para ser um adulto socialmente ajustado e produtivo, o que envolve necessariamente o emprego.

Estas exigências em torno da colocação profissional terminam por trazer certas implicações subjetivas para o jovem que não consegue alcançar este patamar de autonomia profissional e financeira. Aliado a isso, experimenta-se atualmente uma maior precarização do trabalho e uma maior exigência por qualificação e flexibilidade. Elementos que terminam por 
dificultar ou adiar ainda mais a contratação de jovens. Wickert (2006) destaca que os impasses da inserção profissional resultam em impactos nos modos de subjetivação dos jovens, principalmente para aqueles que estão em busca de seu primeiro emprego.

Se o discurso predominante é o da empregabilidade, que coloca sobre as pessoas, e em especial nos jovens, a responsabilidade pelo seu sucesso ou fracasso profissional, o PJA parece se colocar como uma possibilidade de inserção no mercado de trabalho, por garantir a formação e a experiência profissional. Contudo, a equação não parece ser tão direta. Formação e experiência não resultam automaticamente em emprego formal, pois o incremento na oferta de mão-de-obra qualificada não segue necessariamente o mesmo ritmo do aumento na demanda por profissionais qualificados (Andrade, 2008).

Esses aspectos relacionados à dificuldade do jovem em se inserir no mercado, são refletidos na fala de um dos aprendizes, que destaca que o Programa e a experiência na empresa poderão "Facilitar o ingresso do jovem no mercado de trabalho, que é muito difícil né?" (Sexo feminino, 16 anos).

Amazarray, Thomé, Souza, Poletto, e Koller (2009) em estudo sobre aprendizes com contrato em empresa pública encontraram que, para os entrevistados, ser aprendiz é um privilégio de inserção no mercado de trabalho em relação a outros jovens e uma experiência importante para o futuro profissional. O que corrobora os resultados encontrados em nosso estudo, em que os jovens trazem repetidamente o valor do programa para sua futura inserção profissional e ascensão social.

Um elemento destacado como diferencial na sua futura inserção como trabalhador foi o fato de aprender a lidar com o cliente e a trabalhar na empresa. Como demonstra um dos participantes: "Preparar tanto profissionalmente tanto o caráter do jovem. A pessoa muda muito. Amadurece" (Sexo feminino, 16 anos).

Ao mesmo tempo em que trabalho pode ser fonte de amadurecimento psicológico, intelectual e de socialização, complementando a ação da escola para os adolescentes, pode causar o fenômeno da "adultização" (Amazarray et al., 2009; Guimarães \& Romanelli, 2002). Esse destaque dado pelos jovens à necessidade de aprender a se comportar de forma madura e a seguir as regras da empresa, demonstra que, para eles, a formação está focada em aspectos comportamentais e relacionais. Observa-se subjacente às falas dos participantes uma concepção de jovem como aquele imaturo, instável, que precisa ser moldado e aprender a seguir as regras da empresa. Como demonstra a fala a seguir: "Aprender a lidar com os colegas, porque é difícil” (Sexo masculino, 16 anos).

Os aprendizes são orientados em sua formação a como tratar os clientes, sobre o que devem conversar no ambiente de trabalho, como devem se comportar, e por último, é exigido que sejam eficientes no que fazem, desempenhando suas atividades com o máximo de qualidade possível. A partir dos dados observa-se que, em geral, os jovens já perceberam o perfil do empregado que as empresas precisam, e lutam para se enquadrar no perfil.
Segundo Costa (2008), a preocupação fundamental da educação pelo trabalho, no período de formação do jovem trabalhador é que este seja desalienado, concebendo o jovem como sujeito de sua história, como agente de transformação de si e do mundo, através do trabalho. Contudo, pode-se observar que o que tem ocorrido, em muitas situações, é um enquadramento dos mesmos às exigências e demandas do capitalismo, impossibilitando espaços de autonomia e construção de si mesmo enquanto sujeito social. Como afirma um dos jovens: "O ensino de como comportar-se na empresa é o mais importante que a gente aprende" (Sexo feminino, 15 anos). Outro aprendiz destaca que "(...) às vezes eles [funcionários] não gostam muito que a gente pergunte" (Sexo masculino, 17 anos). Esta posição de formação para comportamentos desejáveis e pouco criativos mostra que a formação oferecida ocorre de tal maneira a preparar o aprendiz para funções subalternas, já que, via de regra, em muitas empresas valoriza-se o uso de criatividade em cargos mais elevados, enquanto que os que se colocam em funções subalternas têm pouco espaço para se expressar (Dejours \& Abdoucheli, 1994). Assim, mesmo que admitamos que a formação acabe necessariamente passando por formar pessoas para alimentar o mercado, neste caso formam-se pessoas para, provavelmente, ocupar funções menos reconhecidas e mal remuneradas, contribuindo para a manutenção do status quo.

As falas dos jovens evidenciam que o discurso do protagonismo juvenil é deixado de lado, pois se visa muito mais ao controle social, via disciplinamento (Macedo, 2006). Segundo Soares (2009, p. 6), "considerando os momentos históricos da formação profissional, diríamos que estamos diante de uma nova pedagogia da docilidade". Isso demonstra que, apesar dos avanços teóricos que foram apresentados neste artigo em termos de definição do jovem enquanto sujeito social, as concepções em torno dos jovens enquanto sujeitos passivos, que necessitam de orientação e disciplinarização ainda parecem ser predominantes na prática.

Outra subcategoria que emergiu foi a entrada no PJA em decorrência da necessidade financeira, como auxilio à família de baixa renda e na expectativa em ter um futuro melhor, como destaca uma das aprendizes: "Proporcionar um futuro melhor" (Sexo feminino, 16 anos). Esse aspecto pode estar correlacionado com a renda apresentada pelos aprendizes e o número de pais desempregados.

Isso demonstra que os jovens, ainda na casa dos pais, sofrem as implicações da precarização do trabalho não apenas sobre si, mas também sobre seus pais (desempregados, com empregos informais ou com baixos salários) o que faz com que precisem buscar uma complementação financeira para a família, motivando a entrada antecipada no mercado de trabalho. Essa situação pode ser observada na fala a seguir: "Quem disser que não entrou aqui por causa do dinheiro tá mentindo" (Sexo Masculino, 16 anos).

\section{Avaliação da formação}

No que se refere à avaliação da formação, a maioria dos aprendizes entrevistados julga como um dos aspectos mais 
importantes o reforço aos conteúdos escolares, relatando que recebem apoio e estímulo por parte da instituição formadora para se dedicar aos estudos. Como destaca uma jovem: "Porque eles nos ajudam a se dedicar ao curso" (Sexo Feminino, 16 anos).

Outra dimensão também destacada na formação é o ensino de conteúdos técnicos remetendo-se à aquisição de conteúdos que serão usados na empresa e na futura profissão, como é colocado na fala: "A gente tem que aprender como trabalhar lá, né!?" (Sexo feminino, 18 anos).

A fala dessa jovem corrobora a perspectiva de Frigotto (2001), que atenta para o fato de que as propostas das políticas educacionais, de formação técnico-profissional e os programas de qualificação e requalificação profissional têm se mostrado ideologicamente configurados em programas de capacitação técnica, atropelados pelas demandas, condições econômicas e políticas das organizações.

Os jovens mencionam também o ensino de como se comportar na empresa, justificando que é necessário uma boa postura e comportamento na empresa, mostrando a necessidade que eles sentem de se enquadrar no mercado de trabalho e às regras da empresa, e assim o aprendiz acaba desejando ser o funcionário que a empresa almeja, para que seu emprego possa ser garantido no futuro, sendo esta uma forma também de evitar demissão, ou de facilitar a entrada deste em outra empresa ao final do contrato de aprendiz.

Como se pode observar, a questão do aprendizado emerge na finalidade do PJA, mas aparece fortemente limitado ao aprendizado de normas e do saber lidar com as pessoas; e mais uma vez sobressai nas falas a necessidade da postura e do comportamento quando da avaliação do curso de formação. Ou seja, segundo os jovens, a inserção no PJA tinha como intuito o aprender a seguir as normas da empresa.

Observa-se ainda que, quando vão para o curso propriamente dito, faz-se exatamente isso: se ensina os jovens a se comportarem e a se adequarem. Como destaca um dos aprendizes: "Porque a coisa mais importante é como você lida com as situações na empresa, para que assim você se mantenha nela" (Sexo masculino, 16 anos).

Frigotto (2001) critica o modo como a educação profissional tem sido conduzida, quando afirma que a mesma tem se dado a partir de um enfoque individualista e fragmentado, que não necessariamente habilita o cidadão a um emprego ou profissão, mas que o torne apenas um mero 'empregável' disponível no mercado de trabalho sob os desígnios do capital. O que podemos ver na fala dos jovens é que os cursos visam o enquadramento em modelos profissionais solicitados pelas organizações, não valorizando a questão do protagonismo juvenil.

Quando uma das jovens destaca que “(...) cada um quer só saber de si, cada um quer subir individual" (Sexo Feminino, 16 anos), ela está refletindo acerca das vivências que tem como aprendiz, já submetida ao individualismo e à competitividade, em que há, em certa medida, o esfacelamento das relações intersubjetivas, de coleguismo e cooperação, ferramenta tão importante para sua aprendizagem dentro e fora da empresa.
Outra fala também dá destaque a essa dimensão: "Se a gente pede aos funcionários, eles colocam dificuldade”. (Sexo masculino, 17 anos)

Nessa perspectiva de dualidade na formação, entre o coleguismo e o individualismo, o relacionamento com os colegas de trabalho é visto ora como empecilho à sua prática, ora como um momento de aprendizagem, onde eles repassam como é feito o serviço na empresa. Como destaca uma aprendiz quando questionada sobre os pontos positivos da prática na empresa: "A aprendizagem que eu venho a ter com eles" (Sexo feminino, 17 anos). Ou ainda outra que diz: "Aprendo com eles [os funcionários], olhando como eles trabalham. Me deu uma base importante" (Sexo Feminino, 15 anos).

O que compreendemos é que o aprendiz é orientado a se comportar de determinada maneira que não burle as regras da empresa, onde eles tentam manter um bom relacionamento com os outros funcionários para um bom funcionamento da própria empresa, ou seja, é orientado a ter um perfil para que assim ele possa permanecer nesta. Sugere-se então que essa aprendizagem deve girar em torno da apreensão de elementos práticos que favoreçam sua entrada no mercado de trabalho e do aprendizado de como se comportar docilmente na empresa.

Marx (1982) reflete a importância da relação entre trabalho e formação. Contudo, o autor postulava que essa formação deveria ser libertadora, na medida em que fizesse com que os jovens se reapropriassem do trabalho e rompessem com a dominação capitalista. Mas o que temos visto é que no desenvolvimento das Políticas Públicas de formação profissional para os jovens, tem sido reproduzido o sentido do disciplinamento.

Com isso, não se quer negar a importância de que um jovem recém inserido no mercado de trabalho e na empresa seja treinado quanto às normas a serem seguidas. Questiona-se, sim, o fato de um programa, pensado para ser formador no sentido pleno da palavra, restringir-se ao ensinamento de normas e padrões comportamentais.

\section{Teoria e prática na formação}

No que se refere à aplicabilidade do curso de formação, os aprendizes destacaram a relação dos cursos com a atividade realizada na empresa se dá através do conhecimento de direito e cidadania, que são usados dentro e fora da empresa; e a aprendizagem de como se comportar no contexto organizacional, como é assinalada na fala: "Aprendo a lidar com os problemas do dia a dia" (Sexo Feminino, 22 anos)

Outros aprendizes discordam, afirmam que o curso não ensina conhecimentos utilizados na empresa e justificam que a empresa possui serviços que não são passados nas aulas teóricas. Como destaca a fala de um deles: "A formação dada não ensina conhecimentos utilizados na empresa" (Sexo masculino, 16 anos).

Chama-se atenção para o fato de existir um abismo entre a teoria e a prática, onde vemos que por mais que os conteúdos sejam importantes para o exercício da atividade, eles não dão conta de peculiaridades e imprevistos que se colocam 
na situação de trabalho. Um dos aprendizes destaca que os módulos ministrados no curso de formação não acompanham as necessidades de conteúdos que emergem da prática, sendo considerados atrasados, como demonstra sua fala: "Os módulos estão meio atrasados, era pra focar mais administração e matemática financeira" (Sexo masculino, 16 anos).

O exercício do trabalho é sempre acompanhado de um encontro com o inesperado. Desse modo, é válido refletir se a formação tem dado o suporte para os aprendizes na prática. Pode-se observar que há uma ênfase excessiva nos aspectos comportamentais e até mesmo de reforço escolar, que não é acompanhada na mesma medida pela preocupação em atender às especificidades ao desempenho das funções pelos aprendizes. Há, portanto, uma precedência dos "valores”, das "atitudes" e do relacionamento, das "boas maneiras" e do asseio corporal e pessoal, sobre outras dimensões do processo educativo.

O interessante é que os aprendizes sempre associam a formação aos cursos realizados, não considerando que a empresa e as funções que eles exercem na mesma também são um espaço de formação. Tal aspecto comprova que ainda se persiste com uma visão de qualificação atrelada a cursos estanques, ministrados fora do espaço de trabalho, como se não tivessem nenhuma relação com a prática profissional.

Isso se revela nas falas a seguir dos jovens que apontam que não têm um relacionamento direto com seus supervisores, que se sentem retraídos diante de sua autoridade, ou ainda que são muito cobrados nas empresas, obedecendo à lógica da lucratividade e produtividade, favorecendo, quiçá, uma formação para o individualismo e a competitividade, algo que tende a reforçar as relações sociais desiguais, como aparece na fala: "A gente não tem tanto contato" (Sexo Feminino, 18 anos). Outra aprendiz também reflete sobre esse aspecto: "Receio porque eles ocupam um cargo maior que o nosso, aí a gente fica um pouco retraído" (Sexo Feminino, 17 anos).

Por outro lado, os próprios gestores que deveriam orientar os aprendizes nas empresas também estão submetidos a uma pressão intensa por resultados, contínua formação profissional, sobrecarga de funções e imprevistos na atividade, o que dificulta o estabelecimento de uma relação de ensino - aprendizagem com os aprendizes (Máximo, Araújo, Zambroni-deSouza, \& Alberto, 2011).

Algumas falhas são apontadas exatamente para a formação oferecida pela instituição formadora. Vemos que os fatores levantados pelos aprendizes em sua maioria estão relacionados às técnicas como a melhoria e atualização do módulo e a necessidade de mais informações. Esses elementos dão a entender que existem lacunas quanto à formação voltada para a execução da função na empresa, como vimos em várias falas acima. A fala seguinte atenta para tal situação: "A maioria das aulas são teóricas, acho que [deveriam] colocar aulas práticas" (Sexo feminino, 17 anos).

A formação, muitas vezes, não tem sido conduzida como suporte à prática de trabalho e as variabilidades e imprevistos que ali aparecem, mas como reprodutora das normas e regras organizacionais. Desse modo, é importante destacar que toda formação precisa estar de acordo com o contexto da atividade, para que realmente o jovem se sinta preparado para o exercício de suas funções.

Castro e Aquino (2008) destacam que as políticas de formação técnico-profissional oferecidas aos jovens não têm trazido, historicamente, mudanças significativas no modo como a sociedade os representa. E por isso, os conteúdos dos cursos não estão necessariamente articulados às atividades de trabalho, tendo em vista que o foco principal destes seria o de disciplinar os jovens, tornando-os produtivos.

Também observa-se nas falas dos jovens que as conexões feitas entre os conteúdos ministrados nos cursos e o trabalho referem-se mais ao aspecto comportamental, do que à formação para o trabalho. Dessa forma, os aprendizes estão sendo formados no sentido de preservarem aquele perfil de adequação e enquadramento buscado desde o momento da seleção pelas empresas, o que é criticado por Frigotto (2001), quando afirma que a formação tem se dado a partir de um enfoque individualista e fragmentado, que não necessariamente habilita o cidadão a um emprego ou profissão, mas que o torne apenas um mero 'empregável' disponível no mercado de trabalho sob os desígnios do capital.

A esse respeito, Sposito e Corrochano (2005) ressalta que se evidencia a concepção da juventude passiva e facilmente influenciável, que precisa ser moldada a partir dos princípios dos bons costumes sociais, transmitidos através da relação de trabalho. Marx (1982), por sua vez, afirma que conjugar educação com trabalho não deveria ser sinônimo de treinamento e disciplinamento, mas sim de construção de autonomia, de cidadania e de conquista de espaços sociais.

Em geral, os aprendizes associam a formação apenas aos cursos, não assumindo a prática como elemento formador, fragmentando prática e teoria. Isso corrobora uma visão de que os cursos de formação ministrados fora do espaço de trabalho não têm ligação com a prática profissional. Como aponta Costa (2008), a dimensão produtiva deve estar atrelada a dimensão formativa para as bases de um trabalho educativo, valorizando a consciência do papel do jovem como agente da história, de inter-relação entre o fazer e o saber, entre a ação e a concepção.

\section{Considerações finais}

Observa-se, através dos dados da pesquisa, que a capacitação para o mercado, a necessidade financeira e a formação do caráter do jovem aparecem como categorias centrais nas entrevistas, ganhando menos destaque algo que é absolutamente fundamental para todos, em especial para os jovens: a formação no sentido de construção de sujeitos sociais autônomos que possam ser protagonistas em suas vidas pessoais e na sociedade.

A formação para os aprendizes está intimamente ligada a padrões de comportamentos esperados na empresa, enfocando os aspectos individualistas e competitivos próprios dos 
cenários organizacionais contemporâneos. Desvaloriza-se, assim, a subjetividade do jovem trabalhador, focando numa reprodução de enquadramento ao emprego, de docilização ao perfil organizacional.

Identificou-se que, para os aprendizes, o processo formativo no curso está em grande parte restrito às aulas teóricas ministradas, descolado da prática na empresa, que também é um momento de formação. Mais uma vez é dado o destaque do comportar-se na empresa, onde os valores, atitudes e boas maneiras, como se isso se efetivasse como garantia de uma futura aceitação como empregado efetivo da empresa. Permanecem aqueles que não contestam, não criticam, não inventam, mas cumprem as ordens a contento.

Os aprendizes sinalizam para as lacunas que ficam entre a teoria e prática e a fragmentação dos conhecimentos transmitidos, ou seja, apontam para a necessidade de articulação entre os saberes formais e os saberes práticos dos trabalhadores. Somando-se à ausência de uma formação situada, os jovens ainda apontaram algumas dificuldades na prática devido à convivência com outros funcionários, que nem sempre estão disponíveis à colaboração.

Observamos que os motivos que impulsionaram os jovens ao programa estão de acordo com a proposta do mesmo, descrita no próprio manual da aprendizagem, que seria ampliar as possibilidades de inserção no mercado de trabalho, tornando assim mais promissor o futuro dos jovens. Mas fica o questionamento se há realmente uma preocupação por parte do Estado com a criação de mecanismos que possam facilitar a contratação formal do jovem após o término do contrato de aprendizagem. O que temos visto é que não existem estatísticas oficiais que possibilitem o monitoramento dos índices de jovens que participaram do Programa e que foram contratados posteriormente.

Outra questão observada é que os discursos dos próprios jovens tendem a revelar uma autorresponsabilização pelo seu sucesso ou fracasso, trazendo a problemática para uma perspectiva de discussão micro, quando esse debate deve transcender as dimensões interpessoais. É necessário que haja uma ampliação dos enfoques de discussão e políticas públicas acerca da formação e inserção de jovens no mercado de trabalho, trazendo à tona problemas sociais e políticos mais amplos que atravessam esse fenômeno e que são fundamentais para que se compreenda a relação da juventude com o trabalho. Dessa maneira, pode-se evitar, portanto, uma visão individualista e fragmentada, segundo a qual cabe a cada jovem buscar a qualificação profissional para que consiga se inserir no mercado.

\section{Referências}

Amazarray, M. R., Thomé, L. D., Souza, A. P. L., Poletto, M., \& Koller, S. H. (2009). Aprendiz versus trabalhador: Adolescentes em processo de aprendizagem Psicologia: Teoria e Pesquisa, 25(3), 329-338. doi: 10.1590/ S0102-37722009000300006

Andrade, C. C. (2008). Juventude e trabalho: Alguns aspectos do cenário brasileiro contemporâneo. Ipea: Mercado de Trabalho, 37, 25-32.
Bastos, P. C., \& Carrano, P. C. R. (2004). Juventude e participação: Análise das políticas públicas municipais dirigidas aos jovens na cidade de Niterói. Recuperado de www.anped.org.br/reunioes/27/gt03/p033.pdf.

Camarano, A. A. (2006). Transição para a vida adulta ou vida adulta em transição? Rio de Janeiro: IPEA.

Castro, J. A., \& Aquino, L. (2008). Juventude e políticas sociais no Brasil. Brasília: IPEA.

Constanzi, R. N., Andrade, K., \& Prado, M. (2008). Trabalho decente e juventude no Brasil. Organização Internacional do Trabalho. Recuperado de http:// www.oitbrasil.org.br/topic/decent_work/doc/news_9.pdf

Costa, A. C. G. (2008). Educação. São Paulo: Editora Canção Nova.

Crispim, K. S., \& Godoy, J. H. A. (2010). Juventude e a questão social no contexto das políticas públicas de trabalho e emprego. Revista Eletrônica de Ciências Sociais, 4(9), 134-149.

Dayrell, J. (2003). O Jovem como sujeito social. Revista Brasileira de Educação, 24, 40-52. doi: 10.1590/S1413-24782003000300004

Dejours, C., \& Abdoucheli, E. (1994). Desejo ou motivação? A interrogação psicanalítica sobre o trabalho. In M. I. S. Betiol (Org.), Psicodinâmica do Trabalho (pp. 33-43). São Paulo: Atlas.

Freitas, M. V., \& Papa, F. C. (2008). Políticas públicas: Juventude em pauta. São Paulo: Cortez.

Frezza, M., Maraschin, C., \& Santos, N. S. (2009). Juventude como problema de políticas públicas. Psicologia e Sociedade, 21(3), 313-323. Recuperado de http://www.scielo.br/pdf/psoc/v21n3/a04v21n3.pdf

Frigotto, G. (2001). Educação e trabalho: Bases para debater a educação profissional emancipadora. Perspectiva, 19(1), 71-87.

Frigotto, G. (2008). Educação profissional e capitalismo dependente: O enigma da falta e sobra de profissionais qualificados. Trabalho, Educação e. Saúde, 5(3), 521-536. doi: 10.1590/S1981-77462007000300011

Fundação Perseu Abramo (2004). Perfil da Juventude Brasileira. Recuperado de http://www.fpa.org.br/node/5381.

Gonzáles, R. (2009). Políticas de emprego para jovens: Entrar no mercado de trabalho é a saída? In J. A. Castro, L. M . C. Aquino \& C. C. Andrade (Orgs.), Juventude e políticas sociais no Brasil (pp 111-128). Brasília: Ipea.

Guimarães, N. A. (2004). Trabalho: Uma categoria-chave no imaginário juvenil? In H. W. Abramo \& P. P. M. Branco (Orgs.), Retratos da Juventude Brasileira (pp. 149-174). São Paulo: Instituto Cidadania e Editora da Fundação Perseu Abramo.

Guimarães, R. M., \& Romanelli, G. (2002). A inserção de adolescentes no mercado de trabalho através de uma ONG. Psicologia em Estudo (Maringá), 7, 117-126

Instituto Brasileiro de Geografia e Estatística - IBGE. (2008). Pesquisa nacional por amostra de domicilio - PNAD: Síntese de indicadores. Recuperado de http://www1.ibge.gov.br/home/estatistica/populacao/ trabalhoerendimento/pnad2008/default.shtm.

Laville, C., \& Dionne, J. (1999). A construção do saber: Manual de metodologia da pesquisa em ciências humanas. Porto Alegre: Editora UFMG/ ArtMed.

Lei do Aprendiz no 10.097/2000, de 01 de dezembro de 2005. Altera dispositivos da Consolidação das Leis do Trabalho - CLT. Recuperado de http://www010.dataprev.gov.br/sislex/paginas/42/2000/10097.htm.

Leite, E. M. (2008). Juventude e trabalho: Criando chances, construindo cidadania. In M. V. Freitas \& F. de C. Papa (Orgs.), Políticas públicas: Juventude em pauta (pp. 145-164). São Paulo: Cortez.

Macedo, O. J. V. (2006). O sentido da formação para o trabalho e as expectativas em relação ao futuro por parte dos adolescentes aprendizes (Dissertação de mestrado). Universidade Federal da Paraíba, João Pessoa. Recuperado de http://www.cchla.ufpb.br/ppgp/images/pdf/dissertacoes/orlando_2006.pdf

Machado, V. B. F. (2009). Inserção profissional em tempos de capitalismo globalizado: como jovens estudantes percebem o mundo do trabalho (Dissertação de Mestrado. Centro Federal de Educação Tecnológica de Minas Gerais, Belo Horizonte). Recuperado de http://www2.et.cefetmg. br/permalink/82a58892-5474-11df-9c99-00188be4f822.pdf 
Marx, K. (1999). O Capital: Crítica da economia política (17ª ed., Livro 1., vol. 1). Rio de Janeiro: Civilização Brasileira.

Marx, K. (1982). Para a crítica da economia política. São Paulo: Abril Cultural.

Máximo, T. A. C. O. (2012). Significado da formação e inserção profissional para gestores e aprendizes egressos do programa jovem aprendiz. (Tese de Doutorado - Programa de Pós-Graduação em Psicologia Social da Universidade Federal da Paraíba, João Pessoa).

Máximo, T. A. C. O; Araújo, A. J. S.; Zambroni-de-Souza, P., \& Alberto, M. F. P. (2011). Exigências nos percursos profissionais de gerentes de banco. Psicologia \& Sociedade, 23(1), 66-74. Recuperado de http://www.scielo.br/ $\mathrm{pdf} / \mathrm{psoc} / \mathrm{v} 23 \mathrm{n} 1 / \mathrm{a} 08 \mathrm{v} 23 \mathrm{n} 1$

Ministério do Trabalho e Emprego. (2009). Cartilha do adolescente aprendiz. Paraíba: DRT.

Pais, J. M. (2009). Juventude como fase da vida: Dos ritos de passagem aos ritos de impasse. Saúde e Sociedade, 18(3), 371-381.

Pillotti, F., \& Rizzini, I. (1995). A arte de governar crianças: A história das políticas sociais, da legislação e da assistência à infância no Brasil. Rio de Janeiro: Universidade Santa Úrsula.

Pochmann, M. (1998). A inserção ocupacional e o emprego dos jovens. Coleção ABET - Mercado de trabalho. São Paulo: ABET.

Pochmann, M. (2000). A batalha pelo primeiro emprego. São Paulo: Publisher Brasil.

Santos, D. P. (2006). Relatório de estágio em psicologia social (Universidade Federal da Paraíba, João Pessoa).
Silva, R. M. P. (2006). Programa adolescente aprendiz: Mecanismo efetivo de inserção dos jovens no mercado de trabalho? (Monografia de especialização - Universidade Federal da Paraíba, João Pessoa).

Soares, O. J. (2009). Juventude e trabalho: Notas e reflexões sobre a formação profissional mediada pela "Lei do Aprendiz" (Lei 10.097/00). Trabalho necessário, 7(8), 1-16. Recuperado de http://www.uff.br/ trabalhonecessario/TN08\%20SOARES,\%200.\%20J..pdf.

Sposati, A. (2002). Regulação social tardia: Característica das políticas sociais latino-americanas na passagem entre o segundo e terceiro milênio. VII Congreso Internacional del CLAD sobre la Reforma del Estado y de la Administración Pública, Lisboa, Portugal.

Sposito, M. P., \& Carrano, P.(2003) Juventude e políticas públicas no Brasil. In O. D. León (Org), Políticas publicas de juventude em América Latina (pp 1639). Vinã del Mar: CIDPA.

Sposito, M. P., \& Corrochano, M. C. (2005). A face oculta da transferência de renda para jovens no Brasil. Tempo Social: Revista de Sociologia da USP, 17(2), 141-172.

Vigotski, L. S. (2007). A formação social da mente: O desenvolvimento dos processos psicológicos superiores. São Paulo: Martins Fontes.

Vygotsky, L. S. (1996). Psicologia Infantil. Obras Escogidas IV. Madrid: Visor.

Wickert, L. F. (2006). Desemprego e juventude: Jovens em busca do primeiro emprego. Psicologia Ciência e Profissão, 26(2), 258-269. doi: 10.1590/ S1414-98932006000200008

Manuella Castelo Branco Pessoa, Mestre em Psicologia pela Universidade Federal da Paraíba (UFPB), é Doutoranda em Psicologia Social pela Universidade Federal da Paraíba. Endereço para correspondência: Rua Josiara Telino- 370 Bancários. CEP: 58053-100 João Pessoa-PB. Telefone: (83) 88149294. E-mail: manucastelobranco2@gmail.com

Maria de Fátima Pereira Alberto, Doutora em Sociologia pela Universidade Federal de Pernambuco (UFPE), é Professora Associada II da Universidade Federal da Paraíba- UFPB e do Programa de Pós-Graduação em Psicologia Social (mestrado e doutorado). E-mail: jfalberto@uol.com.br

Thaís Augusta Cunha de Oliveira Máximo, Doutora em Psicologia Social pela Universidade Federal da Paraíba (UFPB), é Professora Adjunta do Departamento de Psicologia da Universidade Federal da Paraíba (UFPB). E-mail: thaisaugusta@gmail.com

Paulo César Zambroni de Souza, Doutor em Psicologia Social pela Universidade do Estado do Rio de Janeiro (UERJ), é Professor do Programa de Psicologia Social/Departamento de Psicologia da Universidade Federal da Paraíba (UFPB). E-mail: paulozamsouza@yahoo.com.br 